\title{
Incidence and risk factors for pre-eclampsia in Jos Nigeria
}

\author{
Jonah Musa ${ }^{1}$, Caleb Mohammed ${ }^{2}$, Amaka Ocheke $^{3}$, Makswhar Kahansim³ ${ }^{3}$ Victor Pam ${ }^{3}$ Patrick Daru ${ }^{3}$
}

1.University of Jos Faculty of Medical Sciences.

2. Kaduna State University Faculty of Medicine, Obstetrics and Gynaecology.

3. University of Jos Faculty of Medical Sciences, Obstetrics and Gynaecology.

\begin{abstract}
Objective: We sought to estimate the incidence and risk factors associated with development of pre-eclampsia (PET) in Jos, Nigeria.

Methods: An open cohort study of singleton pregnant women attending the antenatal clinic of Jos University Teaching Hospital (JUTH), Nigeria between November 2010 and August 2011. Eligible healthy women at $\leq 20$ weeks gestation were enrolled and followed up until delivery or development of pre-eclampsia. Baseline demographic characteristics including weight, height and body mass index (BMI) were collected at enrollment. Incidence, risk factors and hazard ratios for developing PET were estimated with corresponding 95\% confidence intervals and p-values. All statistical analyses were done with STATA version 11, college station, Texas, USA.
\end{abstract}

Results: A total of 2416 pregnant women were screened for eligibility out of which 323 were eligible for inclusion. The incidence of PET was 87.9 per 1,000 pregnancies $(8.8 \%)$. The significant risk factors for PET were previous history of PET $(\mathrm{RR}=5.1,95 \% \mathrm{CI}: 2.2-12.1)$ and BMI at booking $\geq 25 \mathrm{~kg} / \mathrm{m}^{2}$ (RR=3.9, 95\% CI: $\left.1.5-10.0\right)$.

Conclusion: The incidence of PET was relatively high in our cohort in Jos, Nigeria and a previous history of the disease and overweight or obese pregnant women have a significant hazard of developing the disease in the course of gestational follow up. Targeting women with these characteristics for early preventive intervention and close surveillance at the antenatal booking clinic may help in prevention of the disease and its complications.

Keywords: Pre-eclampsia, incidence, risk, hazard, Jos Nigeria.

DOI: https://dx.doi.org/10.4314/ahs.v18i3.16

Cite as: Musa J, Mohammed C, Ocheke A, Kahansim M, Pam V, Daru P. Incidence and risk factors for pre-eclampsia in Jos Nigeria. Afri Health Sci. 2018;18(3): 584-595. https://dx.doi.org/10.4314/ahs.v18i3.16

\section{Introduction}

Hypertensive disorders in pregnancy affects up to $8 \%$ of pregnancies $^{1}$ and are among the leading causes of maternal and neonatal morbidity and mortality worldwide,

\section{Corresponding author: \\ Jonah Musa, \\ University of Jos \\ Faculty of Medical Sciences. \\ Email: drmusaj@yahoo.com, jonahm@unijos.edu.ng}

particularly in developing countries ${ }^{1,2}$. The National Heart Lung and Blood Institute (NHLBI) working group on research on hypertension during pregnancy ${ }^{1}$ defines Pre-eclampsia as a clinical syndrome that occurs after mid-gestation ( $20^{\text {th }}$ week of pregnancy), characterized by de novo appearance of systolic blood pressure $\geq 140 \mathrm{~mm}$ $\mathrm{Hg}$ or diastolic blood pressure of $\geq 90 \mathrm{~mm} \mathrm{Hg}$, accompanied by new-onset proteinuria, defined as $\geq 300 \mathrm{mg}$ per 24 hours. Findings from a recent multicenter study in Nigeria showed that pre-eclampsia/eclampsia is a leading cause of significant maternal morbidity and mortality in Nigeria ${ }^{3}$ and ongoing efforts to improve maternal mortality in Nigeria focuses on capacity building to identify early

(C) 2018 Musa et al. Licensee African Health Sciences. This is an Open Access article distributed under the terms of the Creative commons Attribution License (https://creativecommons.org/licenses/BY/4.0), which permits unrestricted use, distribution, and reproduction in any medium, provided the original work is properly cited. 
features of pre-eclampsia and addressing gaps in appropriate management of the condition during pregnancy ${ }^{4}$.

Since the etiology of pre-eclampsia is not well understood and trials on prevention have been disappointing $^{5,6}$, efforts at clinical prediction based on identifiable risk factors seems a sensible approach to surveillance and prevention of complications due to pre-eclampsia particularly in resource-limited settings. Indeed, delays in diagnosis and access to effective treatment are leading factors responsible for high maternal and perinatal mortality from pre-eclampsia ${ }^{7}$. Additionally, studies have shown the significance of prediction, prevention, diagnosis and treatment among the evidence-based interventions for improving maternal and perinatal outcomes in pre-eclampsia and other hypertensive diseases during pregnancy $^{8}$. Clinical risk prediction research on the development of pre-eclampsia have focused on nulliparous pregnant women and identified risk factors measured at 14-16 weeks gestation including maternal age, mean arterial blood pressure, body mass index, family history of preeclampsia, family history of coronary heart disease and maternal birth weight'. Other previously documented risk factors include systolic blood pressure at entry and pre-pregnancy obesity ${ }^{10}$. However, most of these studies were done in countries outside of Africa and the generalizability of these findings to women in Nigerian settings may be limited.

This study was therefore done to provide data on incidence and risk factors that are predictive of pregnant women developing pre-eclampsia in an antenatal setting of a University Teaching Hospital in Jos, North-Central Nigeria, Africa. We believe these findings will contribute to the body of knowledge on the epidemiology of this disease and may provide valuable information for possible development of a screening check-list and algorithm for triaging booked antenatal clients for close surveillance in order to improve ability of antenatal care providers to diagnose pre-eclampsia early thereby minimizing risk of complications that could result in maternal and perinatal morbidity and mortality in Nigeria.

\section{Methods}

\section{Design and setting}

This prospective open-cohort study was conducted at the antenatal clinic of the Jos University Teaching Hospital, Jos Nigeria, a tertiary academic medical and referral cen- ter located in North-Central Nigeria. At the time of this study, the standard (traditional) model of antenatal care was operational i.e 4 weekly visits for the first 28 weeks; 2 weekly visits until 36 weeks and weekly thereafter until delivery. Those who develop medical complications within the follow up period were admitted into the antenatal ward for specialized care.

\section{Study population}

All pregnant women presenting at the booking visit at $\leq 20$ weeks of gestation estimated using the last normal menstruation date were screened for eligibility to participate in this study. The inclusion criteria were: 1 . Normal blood pressure measurement at the booking visit $(\leq 20$ weeks of gestation), 2. Informed consent to participate in the study with indicated willingness to be followed up until delivery or development of the outcome. Those with significant proteinuria at booking, known hypertensive and high blood pressure readings at $\leq 20$ weeks gestation were excluded from the study. Those who booked for antenatal care after the $20^{\text {th }}$ week of gestation were excluded from the study. Women with chronic medical conditions such as kidney disease, Diabetes mellitus, Sickle cell anemia were excluded.

\section{Participants' enrollment and follow up}

The study was open for enrollment from November 2010 to August, 2011. At enrollment, a detailed questionnaire was administered to each research participant to obtain data on age, parity, date of enrollment, gestational age at enrollment, educational background, smoking and alcohol history, previous abortions, age at marriage, history of infertility and previous history of pre-eclampsia. The booking blood pressure, qualitative urine protein status, weight, and height were also documented for each participant. We also obtained and recorded the HIV test results of each participant. Participant's weight was measured using a standard scale (Seca manufactured by Vogel and Halke, Hamburg, Germany) to the nearest gram. The women were weighed fully clothed with shoes removed. Height was measured without shoes using a Stadiometer (Seca manufactured by Vogel and Halke, Hamburg, Germany) to the nearest centimeter. Urine protein was qualitatively measured using a dip stick (Uripath 2 brand manufactured by Antec diagnostics Limited- www.antecmedicalproducts.com) on a clean catch urine sample passed into a universal bottle. This was done by inserting 
the dip stick into the urine and the result read after 60 seconds comparing it with the standards placed on the container of the dip stick. The possible readings were as follows: Negative, Trace, $+(30 \mathrm{mg} / \mathrm{dl}),++(100 \mathrm{mg} /$ $\mathrm{dl}),+++(300 \mathrm{mg} / \mathrm{dl})$ and $++++(\geq 2000 \mathrm{mg} / \mathrm{dl})$. In this study, significant proteinuria was defined as qualitative urine protein of ++ or more (i.e $100 \mathrm{mg} / \mathrm{dl}$ ).

Blood pressure was measured with the patient seated on a chair. The non-dominant arm was supported at the level of the heart on a table ensuring that no tight clothing constricts the arm. The cuff of the mercury sphygmomanometer (Accoson brand) was placed on the arm with the center of the bladder over the brachial artery. The lower edge of the cuff was placed $2-3 \mathrm{~cm}$ above the point of the pulsation of the brachial artery. The bladder encircled at least $80 \%$ of the arm. The systolic blood pressure was estimated by palpating the radial artery and inflating the cuff until pulsation disappears. The cuff was then deflated and systolic blood pressure estimated. The sphygmomanometer was then inflated $30 \mathrm{mmHg}$ above the estimated systolic needed to occlude the pulse. A stethoscope diaphragm was then placed over the brachial artery and deflated at a rate of $2-3 \mathrm{mmHg} /$ second until regular tapping sounds were heard. The systolic blood pressure was estimated at the level when the first sound was heard and diastolic blood pressure was estimated at the level when the sound muffled (Korotkoff phase IV) and these were measured to the nearest $2 \mathrm{mmHg}$. The follow ups were scheduled to fit into the routine standard antenatal care follow up protocol for the clinic. At each follow up visit, blood pressure, weight and urine protein estimations were repeated and documented for each patient. Follow up was terminated at any gestational age if the woman developed pre-eclampsia or delivery of her baby with or without development of pre-eclampsia.

\section{Primary outcome measure}

The primary outcome was diagnosis of pre-eclampsia as defined $^{1}$ during the follow up time. The follow up time was the period in weeks between the gestational age at enrollment to development of the primary outcome or delivery of baby whichever came first).

\section{Data management and Statistical analysis}

All data collected were entered into an excel Microsoft 2003 template, and coded for relevant statistical analysis. Summary statistics were generated to compare baseline characteristics of women who developed PET to those who did not. We estimated the incidence of PET and the risk ratio of PET for various exposure variables and corresponding 95\% confidence intervals and $\mathrm{p}$-value were estimated. The risk ratio and incident rate ratio for the development of pre-eclampsia were comparable for all the exposure variables, so we reported risk ratio for easy interpretation. We also developed a Cox proportional hazard regression model using follow up time in gestational weeks as a time variable and development of PET as a failure variable to determine the hazard ratio for development of PET for various exposure variables. Variables with significant hazard ratio were subsequently included in a multivariate Cox regression model to determine independent factors associated with significant hazards for development of PET. Relevant Kaplan-Meier graphs were generated to estimate the cumulative incident probability of developing PET. The Log-Rank test was used to assess equality of failure estimates. $P$ values $<0.05$ suggest significant differences in cumulative incident probability of developing PET. All statistical analyses were done using STATA version 11.0, College Station, Texas, USA. Statistical significance were based on $95 \%$ confidence interval and $\mathrm{p}$ value $<0.05$.

\section{Ethical approval}

The study protocol was approved by the Human Subjects Research Ethics Committee of the Jos University Teaching Hospital, Jos.

\section{Results}

During the 10 months study period (November 2010 to August, 2011), a total of 2416 pregnant women were screened for eligibility at the antenatal out-patient clinic of JUTH. A total of 323 pregnant women were enrolled and followed up during the study (Fig. 1 shows study flow chart with details of enrollment). A total of 307 completed follow up and were included in the final analysis of incidence and risk factors for pre-eclampsia. 


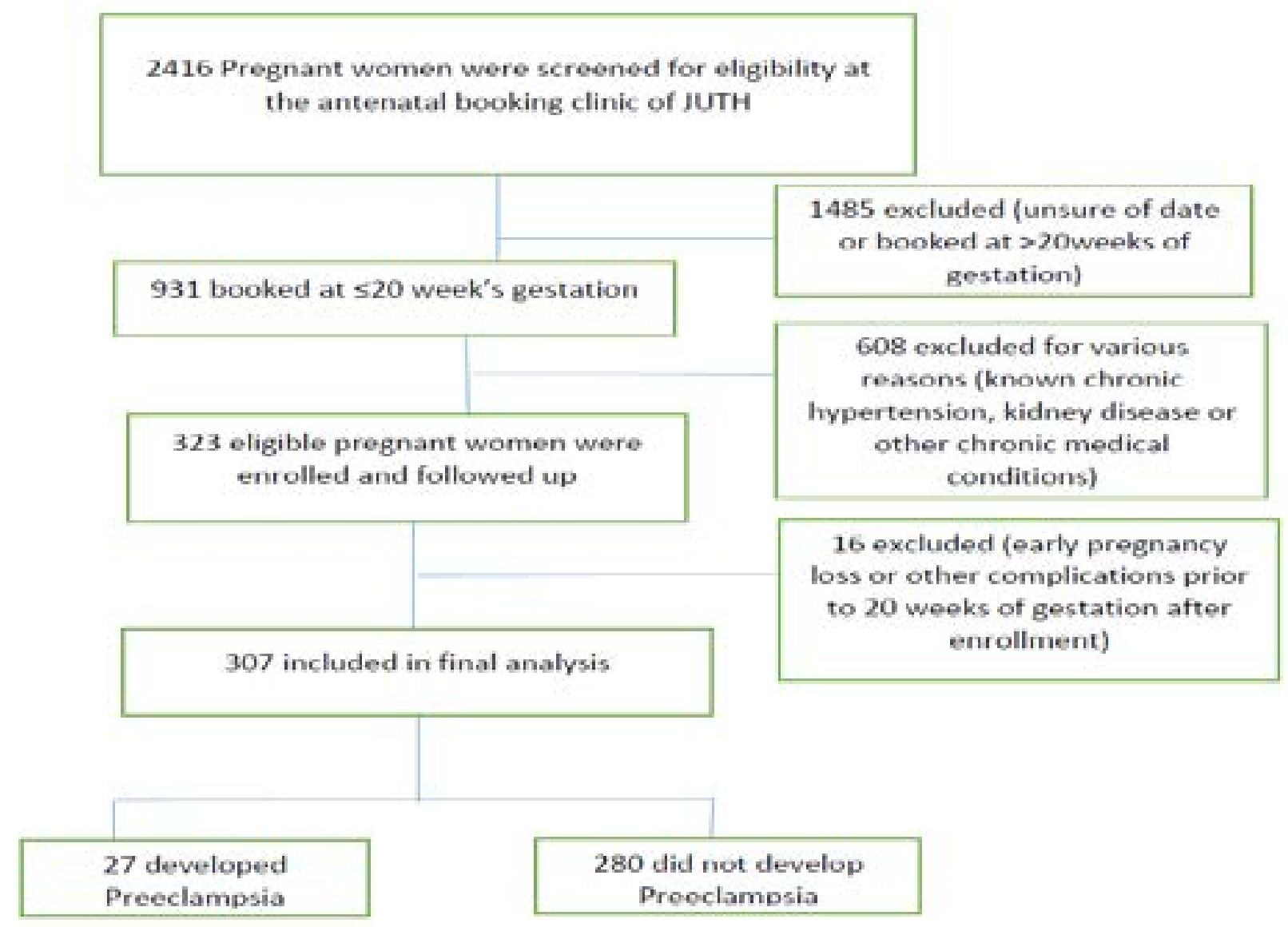

Fig. 1. Study Flow Diagram

Socio-demographic characteristics of study participants

The median age of the cohort was 28 years with interquartile range (IQR) 25-31 years. The median parity and gestational age at booking were 1 (IQR, 0-3) and 15 weeks (IQR, 12-18) respectively. The median systolic and diastolic blood pressures at booking were $110 \mathrm{mmHg}$ (IQR, 110-120) and 70mmHg (IQR, 60-70) respectively. The median body weight and body mass index at booking were $63.5 \mathrm{~kg}$ (IQR, 55-74.5) and $25.2 \mathrm{~kg} / \mathrm{m}^{2}$ (IQR,
22.3-28.7) respectively. Other relevant socio-demographic characteristics of the study cohort were positive HIV status of $4.9 \%$ (95\% CI: 2.4-7.3); Previous history of preeclampsia of 3.6\% (95\% CI: 1.5-5.7); previous history of miscarriage of $32.6 \%$ (95\% CI: 26.6-38.4); and history of infertility of $8.4 \%$ (95\% CI: 4.1-12.6). Almost all the study participants $(99.3 \%)$ were married. Table 1. Shows baseline characteristics of the study participants who developed PET compared to those who did not develop PET in the cohort. 
Table 1: Baseline characteristics of study participants who developed PET compared with those who did not develop PET during the follow up period

\begin{tabular}{|c|c|c|c|c|c|}
\hline Variable & $\begin{array}{l}\text { Developed } \\
\text { PET }\end{array}$ & $95 \% \mathrm{Cl}$ & $\begin{array}{c}\text { Did not } \\
\text { Developed } \\
\text { PET }\end{array}$ & $95 \% \mathrm{Cl}$ & P value* \\
\hline Age (years) & 29.7 & $28.4-31.0$ & 28.4 & $27.8-28.9$ & 0.1468 \\
\hline $\begin{array}{l}\text { Gestational } \\
\text { age at } \\
\text { enrollment } \\
\text { (weeks) }\end{array}$ & 15.6 & $14.3-16.8$ & 14.8 & $14.4-15.2$ & 0.3041 \\
\hline Parity & 1.7 & $1.2-2.1$ & 1.5 & $1.4-1.6$ & 0.4895 \\
\hline Weight (Kg) & 73.4 & $67.5-79.4$ & 65.3 & $63.7-67.0$ & 0.0043 \\
\hline $\mathrm{BMI}\left(\mathrm{Kg} / \mathrm{M}^{2}\right)$ & 28.1 & $26.2-30.0$ & 25.6 & $25.0-26.1$ & 0.0159 \\
\hline $\mathrm{SBP}(\mathrm{mmHg})$ & 113.1 & $108.9-117.4$ & 112.0 & $111.0-113.4$ & 0.6375 \\
\hline $\mathrm{DBP}(\mathrm{mmHg})$ & 71.0 & $67.9-74.2$ & 68.3 & $67.4-69.3$ & 0.0970 \\
\hline
\end{tabular}

BMI-Body Mass Index, SBP-Systolic Blood Pressure, DBP-Diastolic Blood Pressure, Kg-Kilograms, $\mathrm{M}^{2}$ Meter square (*independent student $t$-test for differences in means between two groups)

\section{Incidence of preeclampsia}

Twenty seven (27) out of the 307 normotensive women included in the study developed PET during the study period giving an incidence of 87.9 per 1,000 pregnancies $(8.8 \%)$. The estimated $95 \% \mathrm{CI}$ of the incidence was 56.5 -120.5 cases per 1,000 pregnancies booked at 20 weeks or lesser gestation.

\section{Risk factors for development of pre-eclampsia}

The significant risk factors for the development of preeclampsia in the cohort were previous history of preeclampsia ( $\mathrm{RR}=5.1,95 \% \mathrm{CI}: 2.2-12.1)$ and BMI at booking of $\geq 25 \mathrm{~kg} / \mathrm{m}^{2}(\mathrm{RR}=3.9,95 \% \mathrm{CI}: 1.5-10.0)$. Previous history of miscarriage, HIV infection, history of infertility and parity were not significant risk factors for the development of pre-eclampsia (Table 2 summarizes the point estimates of risk and the associated $95 \%$ confidence intervals and $\mathrm{p}$-values). 
Table 2. Cohort analysis of risk factors for development of Preeclampsia

\begin{tabular}{|c|c|c|c|c|c|}
\hline Exposure variable & $\begin{array}{l}\text { Developed } \\
\text { PET }\end{array}$ & $\begin{array}{l}\text { Did not } \\
\text { develop PET }\end{array}$ & $\begin{array}{l}\text { Risk Ratio } \\
\text { (RR) }\end{array}$ & $95 \% \mathrm{Cl}$ & P-value \\
\hline \multicolumn{6}{|l|}{ Previous PET } \\
\hline Yes & 4 & 6 & 5.1 & $2.2-12.1$ & 0.0004 \\
\hline No & 23 & 274 & & & \\
\hline \multicolumn{6}{|c|}{ Previous Miscarriage } \\
\hline Yes & 8 & 91 & 0.9 & 0.4-1.9 & 0.7422 \\
\hline No & 19 & 189 & & & \\
\hline \multicolumn{6}{|l|}{ Parity category } \\
\hline Nulliparity & 14 & 151 & 0.9 & $0.5-1.9$ & 0.8341 \\
\hline$\geq 1$ & 13 & 129 & & & \\
\hline \multicolumn{6}{|l|}{ History of infertility } \\
\hline Yes & 4 & 21 & 2.0 & $0.7-5.2$ & 0.1844 \\
\hline No & 23 & 259 & & & \\
\hline \multicolumn{6}{|l|}{ HIV status } \\
\hline Positive & 2 & 13 & 1.5 & $0.4-5.9$ & 0.5342 \\
\hline Negative & 25 & 267 & & & \\
\hline \multicolumn{6}{|l|}{ BMI Category } \\
\hline$\geq 25 \mathrm{~kg} / \mathrm{m} 2$ & 22 & 138 & 3.9 & $1.5-10.0$ & 0.002 \\
\hline$<25 \mathrm{~kg} / \mathrm{m} 2$ & 5 & 142 & & & \\
\hline
\end{tabular}

In a univariate Cox proportional regression model, the factors associated with a significant hazard of developing pre-eclampsia during the gestational follow up time were previous history of pre-eclampsia ( $\mathrm{HR}=5.5,95 \% \mathrm{CI}$ : 1.9-16.0) and BMI at booking of $\geq 25 \mathrm{~kg} / \mathrm{m}^{2}$ (HR=3.8, 95\% CI: 1.5-10.1). Previous history of miscarriage, HIV infection, history of infertility and parity were not signif- icant risk factors for the development of pre-eclampsia. In the final multivariate Cox regression model including previous history of pre-eclampsia, BMI category $\geq 25$ $\mathrm{kg} / \mathrm{m}^{2}$, and parity (Nulliparous); previous history of preeclampsia (HR $=7.9 ; 95 \% \mathrm{CI}: 2.5-25.0)$ and $\mathrm{BMI} \geq 25 \mathrm{~kg} /$ $\mathrm{m}^{2}(\mathrm{HR}=4.6$; 95\% CI: 1.7-12.5) were independently associated with significant hazard of developing pre-eclampsia (Table 3). 
Table 3. Univariate and multivariate Cox regression of the factors associated with hazard of developing preeclampsia in the cohort

\begin{tabular}{lllll}
\hline Exposure variable & Unadjusted HR (95\% Cl) & P-Value & Adjusted HR (95\% Cl) & P-value \\
Previous preeclampsia & $5.5(1.9-16.0)$ & 0.002 & $7.9(2.5-25.0)$ & 0.001 \\
$\mathrm{BMI} \geq 25 \mathrm{~kg} / \mathrm{m} 2$ & $3.8(1.5-10.1)$ & 0.007 & $4.6(1.7-12.5)$ & 0.003 \\
Parity (Nulliparous) & $0.9(0.4-2.0)$ & 0.841 & $1.6(0.7-3.6)$ & 0.281 \\
Previous miscarriage & $0.8(0.4-1.8)$ & & & - \\
HIV positive & $1.5(0.3-6.2)$ & 0.585 & - & - \\
History of infertility & 2.0 (0.6-6.9) & 0.601 & - & - \\
\hline HR (Hazard Ratio); BMI (Body Mass Index) & & & & \\
\hline
\end{tabular}

Similarly, Fig.2 and 3 respectively shows the Kaplan-Meier failure estimates of the cumulative incident probability for developing pre-eclampsia for women with history of previous pre-eclampsia and those with BMI $\geq 25 \mathrm{~kg} / \mathrm{m}^{2}$ at booking. 
Fig. 2. Kaplan-Meier of cumulative incident probability of developing PET among pregnant women with previous history compare to those with no previous history of PET during gestational follow up (Log-rank $p$-value $=0.001$ )

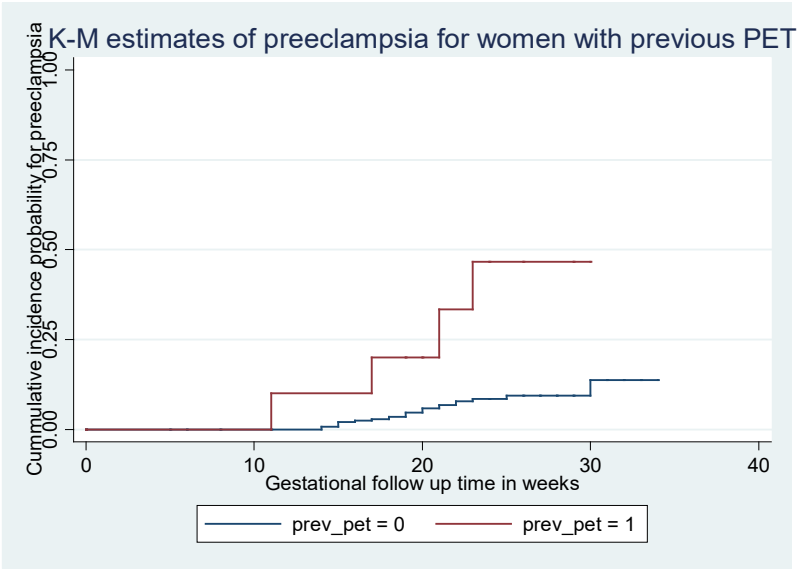

Legend: Prev_pet $=0$ (No previous history of PET); pre_pet=1 (previous history of PET)

Fig. 3. Kaplan-Meier of cumulative incident probability of developing PET among pregnant women with overweight or obese BMI compare to those with normal or underweight BMI during gestational follow up (Log. rank p-value $=0.003$ )

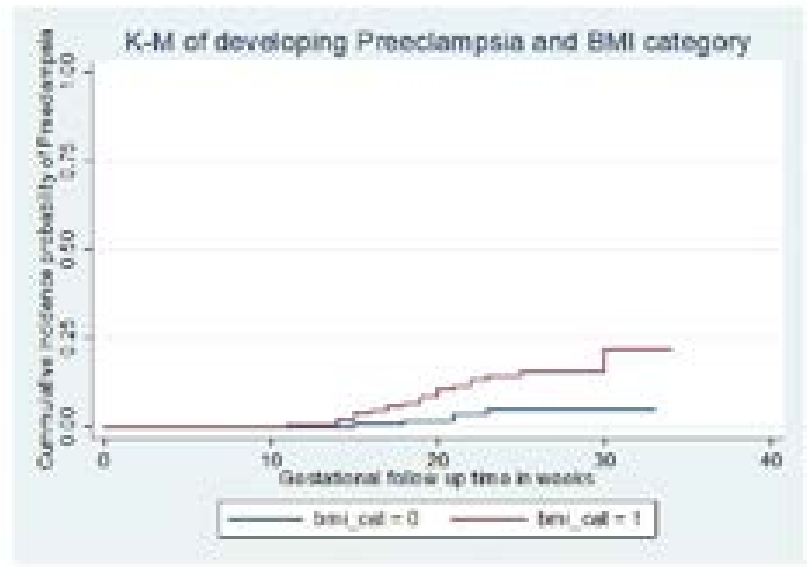

Legend: bmi_cot $=0$ (normal or underweight); bmi_cat $=1$ (overweight or obese) 


\section{Discussion}

In this single institutional open cohort study of normotensive singleton pregnant women enrolled at $\leq 20$ weeks of gestation, we found the incidence of pre-eclampsia of $8.8 \%$ or 87.9 cases per 1,000 pregnancies. We also found that women with previous history of pre-eclampsia and body mass index of $>25 \mathrm{~kg} / \mathrm{m}^{2}$ estimated at $\leq 20$ weeks of gestation had a significantly higher risk and hazard of developing pre-eclampsia during the gestational follow up time.

The relatively high incidence in our cohort reflects the growing burden of pre-eclampsia in Nigeria and most developing countries. The reported incidence of preeclampsia varies from one setting to another ranging between 3-5\% in most industrialized countries ${ }^{11}$ and $2-10 \%$ world-wide ${ }^{12}$. A large multi-center cohort study of healthy nulliparous women with singleton pregnancies found an incidence of pre-eclampsia of $5.3 \%$. The variation in incidence has been linked to variation in season of study, gestational age at diagnosis and severity of PET ${ }^{11,13}$. Also, there is generally a higher prevalence of pre-eclampsia in developing countries compared to developed industrialized countries of the world with a reported prevalence ranging between $2 \%$ and $16.7 \%$ in Nigeria ${ }^{12}$. Our findings confirm the high burden of this significant cause of maternal and neonatal morbidity and mortality in our population and the need to design and implement best strategies to improve outcome.

There are limited longitudinal studies focusing on the incidence of pre-eclampsia in Nigeria. The few longitudinal studies estimated the incidence of hypertensive disease in pregnancy in general and also the incidence of pre-eclampsia. The study done in a core Northern setting found an overall incidence of hypertensive disorder in pregnancy of $17 \%$ and incidence of pre-eclampsia was $6 \%{ }^{14}$. Similarly, the cohort study done in a South Western Nigerian population focusing on the influence of duration of sexual cohabitation on the risk of hypertension in nulliparous parturient ${ }^{15}$ found an incidence of $28.93 \%$ for gestational hypertension and $4.13 \%$ for pre-eclampsia. The slight variation in the incidence of pre-eclampsia reported in the North-Western population of $6 \%{ }^{14}$, the
South-Western population of $4.13 \%{ }^{15}$ compared to our finding of $8.8 \%$ in the North-Central population shows the diversity of our population characteristics within the country. The differences could also be explained by the sample sizes and the fact that previous studies focused on nulliparous women only.

Our study included women of all parity categories and unlike previous reports showing nulliparity ${ }^{11,16}$ as a significant risk factor for pre-eclampsia, our data did not show a significant difference in the risk of pre-eclampsia with parity. The significant risk factors for the development of pre-eclampsia in our cohort were previous history of pre-eclampsia and a $\mathrm{BMI} \geq 25 \mathrm{~kg} / \mathrm{m}^{2}$ estimated at $\leq$ 20 weeks of gestation. Women with previous history of pre-eclampsia had a five times greater risk of developing PET compared to those with no prior history $(\mathrm{RR}=5.1$, 95\% CI: 2.2-12.1). Studies including only nulliparous women will miss this important risk factor. However, even in nulliparous women, those with a family history of pre-eclampsia have been noted to have a significant risk of developing the disease $e^{9,11,17}$. A similar study done in Northern Nigeria found that previous history of preeclampsia was associated with a four-fold greater risk of development of PET compared to those with no prior history ${ }^{14}$. Also, women who were overweight or obese at $\leq 20$ weeks gestation were about four-fold greater risk of developing PET in the course of gestation compared to those who were of normal weight or underweight $(\mathrm{RR}=3.9,95 \% \mathrm{CI}: 1.5-10.0)$.

The impact of maternal obesity and adverse pregnancy outcomes have been documented ${ }^{18}$ and a recent systematic review and meta-analysis on maternal body mass index and risk of birth and maternal health outcomes in low-and middle-income countries further confirms the attributable risk of maternal overweight and obesity with adverse maternal health outcomes ${ }^{19}$. The systematic review and meta-analysis showed that compared with mothers with normal BMI, overweight or obese mothers were at increased odds of gestational diabetes, pregnancy induced hypertension, pre-eclampsia, caesarean section and postpartum hemorrhage ${ }^{19}$. The study results suggested that preventing maternal obesity in the population could reduce the burden of gestational diabetes, pregnan- 
cy induced hypertension and pre-eclampsia by $14-35 \%{ }^{19}$. Epidemiologic studies done in Nigeria have also documented that maternal obesity is a significant predictor of pre-eclampsia in our population ${ }^{14,16}$. Our study findings further lend credence for health education on pre-pregnancy weight control as a strategy for improving maternal and perinatal outcome. It also supports the practice of routine screening for personal history of pre-eclampsia and BMI among risk factors for development of preeclampsia as recommended in the National Institute for Health and Clinical Excellence clinical guidelines for antenatal care for healthy pregnant women ${ }^{20}$. Indeed, a recent committee opinion of the American College of Obstetricians and Gynecologist (ACOG) supports that screening for pre-eclampsia with detailed history risk assessment is currently the best and only recommended screening approach for pre-eclampsia ${ }^{21}$.

The risk assessment approach based on identified epidemiologic risk factors is important for decision making to implement early those interventions that are effective for preventing pre-eclampsia. For instance, women with identified risk factors for pre-eclampsia have been shown to benefit from early intervention with low-dose aspirin started at or before 16 weeks of gestation ${ }^{22}$. This systematic review and meta-analysis ${ }^{22}$, demonstrated that starting low-dose aspirin at $\leq 16$ weeks gestation had significant reduction in pre-eclampsia by $53 \%$ with a pooled relative risk of $0.47,95 \%$ confidence interval $0.34-0.65$ in the intervention compared to placebo. Low-dose aspirin also significantly reduce risk of intrauterine growth restriction with a pooled relative risk of $0.44 ; 95 \% \mathrm{CI}$ : $0.30-0.65^{22}$. Additionally, a recent guideline issued by the US Preventive Service Task Force recommended the use of low-dose aspirin after 12 weeks of gestation in women with high risk factors for pre-eclampsia ${ }^{23}$.

It is worth noting that $32.6 \%$ of our study cohort reported past history of miscarriage. The proportion of pregnant women with this past pregnancy event was similar to the $29.64 \%$ documented in a previous study in South Western Nigeria ${ }^{15}$. Our data showed that previous history of abortion/miscarriage did not significantly affect the risk of developing pre-eclampsia (Table 2 and 3). Similar findings have been reported in Nigeria ${ }^{15}$, with previous history of abortion having no significant effect on the

African Health Sciences Vol 18 Issue 3, September, 2018 hazard of pre-eclampsia (HR=1.05, 95\% CI: 0.82-1.35). However, sub-group analysis showed same paternity abortion had a significant protective effect (HR $=0.71$, 95\% CI: $0.55-0.93$ ) on pre-eclampsia ${ }^{15}$. The clinical implication of the possible epidemiologic association of previous abortion/miscarriage with development of pre-eclampsia requires further investigation.

The major strength of our study is the cohort design with longitudinal follow up data from enrollment to development of outcome. Although our study was done in a single institution in Jos Nigeria, we feel that the cosmopolitan nature of our clinical setting allows for generalizability of our findings to the population of women in most North-Central region of Nigeria. Also, given the large differences in incidence of PET between the BMI categories, and other risk factors in our study sample, our sample size of 307 pregnant women who completed the follow up provided more than $80 \%$ statistical power to detect the effect sizes found in our study. We hope a future larger multi-center cohort study may confirm our findings and improve the certainty of our statistical estimates. However, we acknowledge the relatively poor correlation between the point-of-care dipstick estimation of proteinuria used in this study with the gold standard of a 24-hour urine protein estimation ${ }^{24}$. Therefore, future studies on pre-eclampsia should use more reliable quantitative methods for estimation of proteinuria other than the qualitative point-of-care dipstick method.

\section{Conclusion}

We found a relatively high incidence of PET among pregnant women in Jos Nigeria and previous history of the disease and overweight or obese pregnant women have a significant hazard of developing the condition during gestational follow up. Our antenatal care services should be organized to include a screening checklist for identification of pregnant women with these epidemiologic risk factors and others documented in the literature. Primary health care facilities should be supported to do routine screening for these risk factors and those identified should commence low-dose aspirin and get referred to secondary or tertiary health care facilities for close monitoring till delivery.

\section{Conflict of interest}

The authors have no conflict of interest to declare. 


\section{References}

1. Roberts JM, Pearson G, Cutler J, Lindheimer M. Summary of the NHLBI Working Group on research on hypertension during pregnancy. Hypertension. 2003;41(3 I):437-45. PubMed.

2. Ghulmiyyah L, Sibai B. Maternal Mortality From Preeclampsia/Eclampsia. Semin Perinatol. Elsevier Inc; 2012;36(1):56-9.

3. Oladapo O, Adetoro O, Ekele B, Chama C, Etuk S, Aboyeji A, et al. When getting there is not enough: a nationwide cross-sectional study of 998 maternal deaths and 1451 near-misses in public tertiary hospitals in a low-income country. BJOG An Int J Obstet Gynaecol. 2015;DOI: 10.11 .

4. Otolorin E, Gomez P, Currie S, Thapa K, Dao B. Essential basic and emergency obstetric and newborn care: From education and training to service delivery and quality of care. Int J Gynecol Obstet. Elsevier B.V.; 2015;130:S4653.

5. Sibai BM. Prevention of preeclampsia: a big disappointment. Am J Obstet Gynecol. 1998;179(5):1275-8.

6. Steve Caritis, Baha Sibai, John Hauth, Marshall D. Lindheimer, Mark Klebanoff, Elizabeth Thom, Peter VanDorsten, Mark Landon, Richard Paul, Menachem Miodovnik, Paul Meis GT. Low-Dose Aspirin to Prevent Pre-eclampsia in Women at High Risk. $N$ Engl J Med. 1998;338(11):701-5. PubMed.

7. Firoz T, Sanghvi H, Merialdi M, von Dadelszen P. Pre-eclampsia in low and middle income countries. Best Pract Res Clin Obstet Gynaecol. Elsevier Ltd; 2011;25(4):53748.

8. Von Dadelszen P, Ansermino JM, Dumont G, Hofmeyr GJ, Magee L a., Mathai M, et al. Improving maternal and perinatal outcomes in the hypertensive disorders of pregnancy: A vision of a community-focused approach. Int J Gynecol Obstet. International Federation of Gynecology and Obstetrics; 2012;119(SUPPL.1):S30-4.

9. North R a, McCowan LME, Dekker G a, Poston L, Chan EHY, Stewart AW, et al. Clinical risk prediction for pre-eclampsia in nulliparous women: development of model in international prospective cohort. BMJ. 2011;342:d1875.

10. Sibai BM, Gordon T, Thom E, Caritis SN, Klebanoff M, McNellis D, et al. Risk factors for preeclampsia in healthy nulliparous women: a prospective multicenter study. The National Institute of Child Health and Human Development Network of Maternal-Fetal Medicine Units. Am J Obstet Gynecol. 1995;172(2 Pt 1):642-8. PubMed.

11. Hutcheon JA, Lisonkova S, Joseph KS. Epidemiology of pre-eclampsia and the other hypertensive disorders of pregnancy. Best Pract Res Clin Obstet Gynaecol. Elsevier Ltd; 2011;25(4):391-403.

12. Osungbade KO, Ige OK. Public health perspectives of pre-eclampsia in developing countries: implication for health system strengthening. J Pregnancy. 2011;2011:481095.

13. Lisonkova S, Joseph KS. Incidence of pre-eclampsia: Risk factors and outcomes associated with early-versus late-onset disease. Am J Obstet Gynecol. Elsevier Inc, 2013;209(6):544.e1-544.e12.

14. Singh S, Ahmed E, Egondu S, Ikechukwu N. Hypertensive disorders in pregnancy among pregnant women in a Nigerian Teaching Hospital. Niger Med J. 2014;55(5):384 PubMed.

15. Olayemi O, Strobino D, Aimakhu C, Adedapo K, Kehinde A, Odukogbe AT, et al. Influence of duration of sexual cohabitation on the risk of hypertension in nulliparous parturients in Ibadan: A cohort study. Aust New Zeal J Obstet Gynaecol. 2010;50(1):40-4.

16. Anorlu RI, Iwuala NC, Odum CU. Risk factors for pre-eclampsia in Lagos , Nigeria. 2005; (March):278-82.

17. Bezerra PCFM, Leão MD, Queiroz JW, Melo EMD, Pereira FVM, Nóbrega MH, et al. Family history of hypertension as an important risk factor for the development of severe pre-eclampsia. Acta Obstet Gynecol Scand. 2010;89(5):612-7.

18. Pallasmaa N, Ekblad U, Gissler M, Alanen A. The impact of maternal obesity, age, pre-eclampsia and insulin dependent diabetes on severe maternal morbidity by mode of delivery-a register-based cohort study. Arch Gynecol Obstet. 2014;311-8 PubMed.

19. MM Rahman, SK. Abe, M Kanda, S Narita, MS Rahman, V Bilano, E Ota SG and KS. Maternal body mass index and the risk of birth and maternal health outcomes in low- and middle-income countries: a systematic review and meta-analysis. Obes Rev. 2015;16:758-70.

20. Royal College of Obstetrician and Gynaecologist. Pregnancy and complex social factors : A model for service provision for pregnant Pregnancy and complex so- 
cial factors : A model for service provision for pregnant women with complex social factors. National Institute of Health and Clincal Excellence Clinical Guideline 62. 2010.

21. American College of Obstetricians and Gynecologist. First-Trimester Risk Assessment for Early-Onset preeclampsia. Obs Gynecol. 2015;126(Committee Opinion No. 638):e25-7.

22. Bujold, Emmanuel MD, MSc, Roberge, Stéphanie, MSc, Yves Lacasse, MD, MSc, Marc Bureau, MD, Franc ${ }_{s}$ oisAudibert, MD, MSc, Sylvie Marcoux, MD, PhD,
Jean-Claude Forest, MD, PhD, and Yves Gigue 're, MD P. Prevention of Pre-eclampsia and Intrauterine. Obstet Gynecol. 2010;116(2):402-14. PubMed.

23. LeFevre ML. Low-Dose Aspirin Use for the Prevention of Morbidity and Mortality From Pre-eclampsia: U.S. Preventive Services Task Force Recommendation Statement. Ann Intern Med. 2014;161(11):819.

24. Waugh JJS, Bell SC, Kilby MD, Blackwell CN, Seed P, Shennan AH, et al. Optimal bedside urinalysis for the detection of proteinuria in hypertensive pregnancy: A study of diagnostic accuracy. BJOG An Int J Obstet Gynaecol. 2005;112(4):412-7. 